www.jmscr.igmpublication.org Impact Factor 5.244

Index Copernicus Value: 83.27 ISSN (e)-2347-176x ISSN (p) 2455-0450 crossref DOI: _https://dx.doi.org/10.18535/jmscr/v4i11.21

\title{
Assessment of Vein Intima-Media Thickness in Determining Maturity of AV Fistula
}

\author{
Authors \\ Dr Talluri Bhavishya ${ }^{1}$, Dr Ramesh Kumar Rudrappa ${ }^{2}$ \\ ${ }^{1}$ Post Graduate, ${ }^{2}$ Professor and Head of Department \\ ${ }^{1,2}$ Department of Radio-diagnosis, Sri Manakula Vinayagar Medical College and Hospital, Madagadipet, \\ Kalitheerthalkuppam, Puducherry-605107, India \\ Corresponding Author
}

Dr T.Bhavishya

Department of Radio-diagnosis, Sri Manakula Vinayagar Medical College and Hospital, Madagadipet,

Kalitheerthalkuppam, Puducherry-605107

Email: talluribhavishya@gmail.com, Contact no.9626598645

\section{ABSTRACT}

Vascular access is a hemo-dialysis patient's lifeline. Two types of permanent vascular access are designed which include the arterio-venous fistula and the arterio-venous graft. After surgical creation, arteriovenous fistulas typically require several months of maturation for the draining vein to dilate and the arterio-venous blood flow to increase. The criteria for AV fistula maturation is vein diameter of $4 \mathrm{~mm}$ and access blood flow volume of $500 \mathrm{ml} / \mathrm{min}$ by using Doppler. Here we assess the intima-media thickness of the vein in determining maturity of AV fistula.

Purpose- To determine cannulation readiness of AV fistula by determining vein intima-media thickness.

Materials and methods- Institutional review board approval and informed consent were obtained for this study. The study is a cross-sectional study at our hospital tertiary health care set up.

Statistical Analysis - A Chi-square test is used to find an association between variables (gender, diabetic and hypertensive status).

Results and Conclusion- The conclusions drawn are those cases with intima-media thickness $</=0.20 \mathrm{~mm}$ are not matured, while those cases with intima-media thickness $>/=0.26 \mathrm{~mm}$ were matured and those cases with intima-media thickness between 0.21-0.25mm were matured only by vein diameter.

KEYWORDS- Intima-media thickness, Vein, maturity, arteriovenous fistula.

\section{INTRODUCTION}

A vascular access lets large amounts of blood flow continuously during hemodialysis treatments to filter as much blood as possible per treatment (1). A vascular access makes life-saving hemodialysis treatments possible. Dialysis is a lifesaving process whereby removing wastes, salts and excess fluid from the blood and is used primarily as an artificial replacement for lost kidney function in people with renal failure. Hemo-dialysis is a treatment for kidney failure that uses a machine to send the patient's blood through a filter, called a dialyzer, outside the body. The kidney failure and the eventual process of dialysis is a costly affair with significant risks of morbidity and mortality. 
The dialysis outcome quality initiative guidelines tell that creation of primary arterio-venous fistula is possible in only $50 \%$ of the patients ${ }^{(2,3)}$.The matured arterio-venous fistula outperforms arterio-venous graft in having higher patency rates, freedom from infection and low maintenance costs ${ }^{(4)}$. To increase the use of native arterio-venous fistulas, for early detection of access dysfunction and subsequently needed intervention and for reducing the rate of access failure periodic and early monitoring is required ${ }^{(5,6)}$. Duplex ultrasound is considered superior as it provides information both on the morphology and the function of vascular access. In addition, it offers an advantage of being non-invasive, bedside procedure with less cost and no need of radio-contrast $^{(6)}$. Hence ability to predict whether arterio-venous fistula is going to mature eventually is important. So, I intend to study the role of ultrasound in evaluating the maturity of arterio-venous fistulas using vein intima-media thickness contrary to the already being used maturation criteria (vein diameter and access blood flow volume).

\section{OBJECTIVES}

The study is to evaluate arterio-venous fistula maturity using ultrasound by measuring vein intima-media thickness for hemo-dialysis patients within 4 months of placement of arterio-venous fistula at our institution.

\section{MATERIALS AND METHODS}

INCLUSION CRITERIA: All patients aged about 15-80 years within 4 months placement of arteriovenous fistulas for hemo-dialysis are included in our study. The patients are taken up for a period of 18 months.

EXCLUSION CRITERIA: All patients postplacement of arterio-venous fistula with complications such as infection, stenosis, thrombosis, steal phenomenon, aneurysm and pseudoaneurysm formation are excluded from our study.
SAMPLING: All patients coming for hemodialysis within 4 months of placement of vascular access.

STATISTICAL ANALYSIS: Frequencies and percentages are calculated. A Chi-square test is used to find an association between variables (gender, diabetic and hypertensive status). Mean and standard deviation are calculated for vein intima media thickness

Independent $\mathrm{t}$ test are done to compare mean and standard deviation between groups. Data will be entered and analyzed using Epi info version 7 software. $\mathrm{p}$ value < than 0.05 will be considered to be statistically significant.

Vein intima-media thickness was measured using Philips HD 11 ultrasound machine with a linear probe of frequency range $7-12 \mathrm{Mhz}$ to assess the maturity of arteriovenous fistula.

\section{ETHICAL CONSIDERATIONS}

The Ethical approval was obtained from the Institute Ethics committee. All the ethical principles are adhered in the study.

PROCEDURE: The feeding artery, anastomoses and the entire draining vein should be scanned, and the minimum diameter should be measured. The depth of the anterior wall of the AVF from the skin surface is also measured.The AVF feeding artery, anastomosis, and draining vein are analyzed, using spectral and color Doppler. The depth of the anterior wall of the draining vein from the skin surface is measured in the forearm for a forearm AVF and in the upper arm for an upper arm AVF. If the depth of the vein is greater than $0.5 \mathrm{~cm}$, it will be too deep for easy access with a 15-gauge needle.

Blood flow is measured in the AVF in $\mathrm{ml} / \mathrm{min}$, using the volume flow measurement function of the Duplex instrument. If the blood flow equals or exceeds $500 \mathrm{~mL} / \mathrm{min}$, the likelihood of fistula adequacy is near twice as great as with lower flow rates.

Vein diameter of minimum $4 \mathrm{~mm}$ and blood flow velocity of minimum $500 \mathrm{ml} / \mathrm{min}$ are considered sonological criteria for the maturity of arterio-venous fistulas. Vein intima-media thickness is taken as maturation criteria and 


\section{JMSCR Vol||04||Issue||11||Page 13644-13651||November}

correlated with already established criteria of vein diameter and access blood flow volume. The combination of the echogenic line interface and hypoechoic band represented the intima-media thickness. The machine used for imaging is PHILIPS HD 11XE, linear transducer probe with a frequency range of 7 megahertz to 12 megahertz.

\section{RESULTS}

Of the total 55 cases done, there was good correlation of the number of matured(46) and immatured (9) cases using intima-media thickness and access blood volume criteria (Table 2). 46 cases were matured by both intima-media thickness and vein diameter. 9 immatured cases were noted of which 6 were matured by vein diameter but not by intima-media thickness and 3 were not matured by both intima-media thickness and vein diameter(Table 3). The intima-media thickness were categorized into three subdivisions based on their maturation status and there was good correlation between access blood flow volume and intima-media thickness (Table 4). With Intima-media thickness of $>/=0.26 \mathrm{~mm}, 46$ cases were matured by both access blood flow volume and intima-media thickness. With Intima- media thickness $</=0.25 \mathrm{~mm}, 9$ cases were not matured by both access blood flow volume and intima-media thickness. With Intima-media thickness of $</=0.20 \mathrm{~mm}, 3$ cases were not matured by both vein diameter and intima-media thickness. With Intima-media thickness $>/=$ $0.21 \mathrm{~mm}, 52$ cases were matured by both vein diameter and intima-media thickness(Table 5). The conclusions that were drawn are those cases with intima-media thickness $</=0.20 \mathrm{~mm}$ are not matured, while those cases $>/=0.26 \mathrm{~mm}$ were matured and those cases with intima-media thickness between $0.21-0.25 \mathrm{~mm}$ were matured only by vein diameter.

Of the 55 cases, $84 \%$ of the vascular access created were of radiocephalic fistula while $13 \%$ were contributed by brachiocephalic fistula and remaining $4 \%$ by brachiobasilic transposition. More cases of radiocephalic fistula created could relate to the low incidence of complications associated with it, patients pre-placement examination status of the vessels and depends on the surgeon's choice and expertise in vascular surgeries.

The mean intima media thickness obtained was $0.28 \mathrm{~mm}$ with standard deviation of $0.04 \mathrm{~mm}$ (TABLE 1)

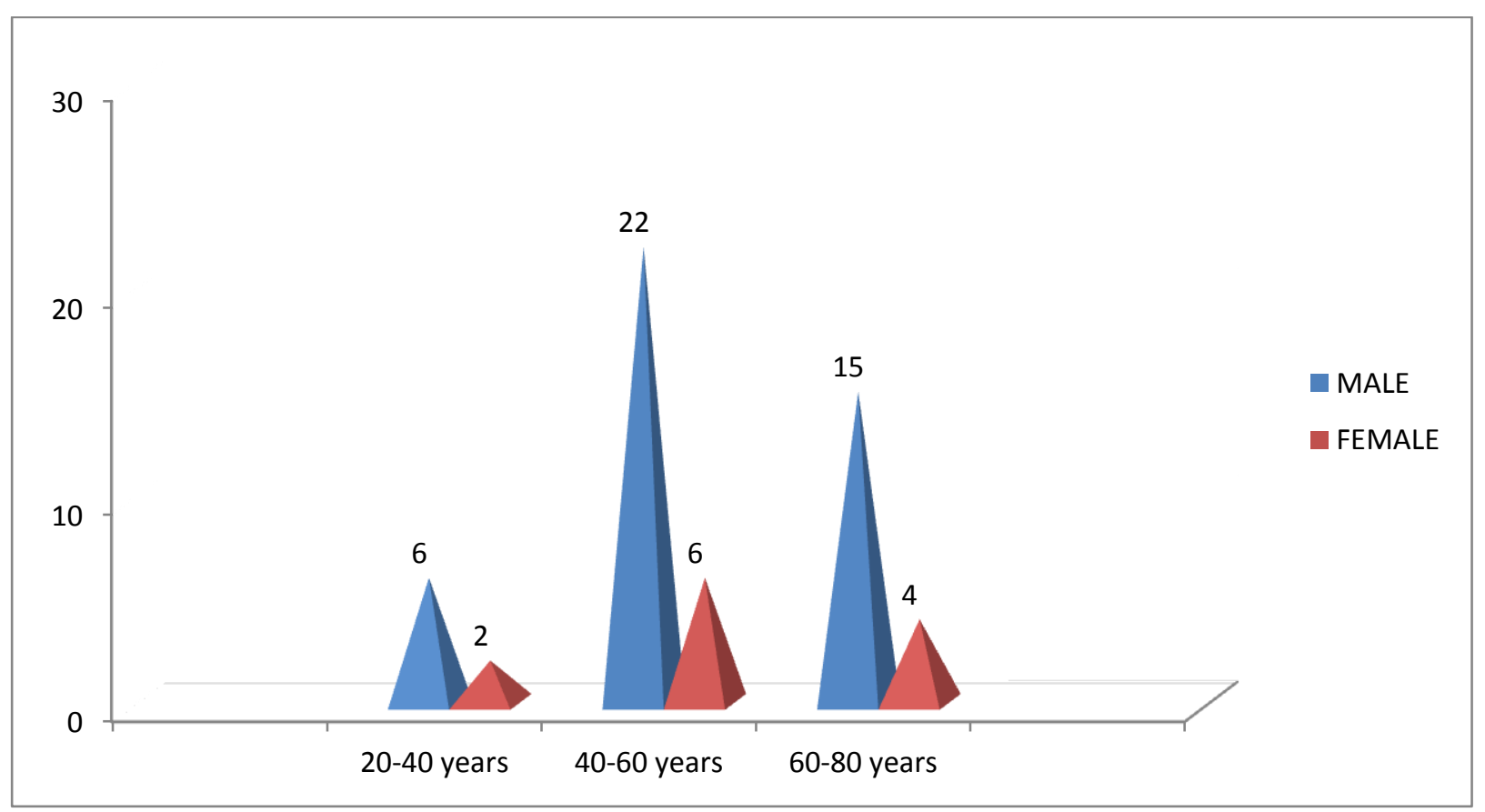

Figure 1- Distribution of Study Population According to Sex and Age 


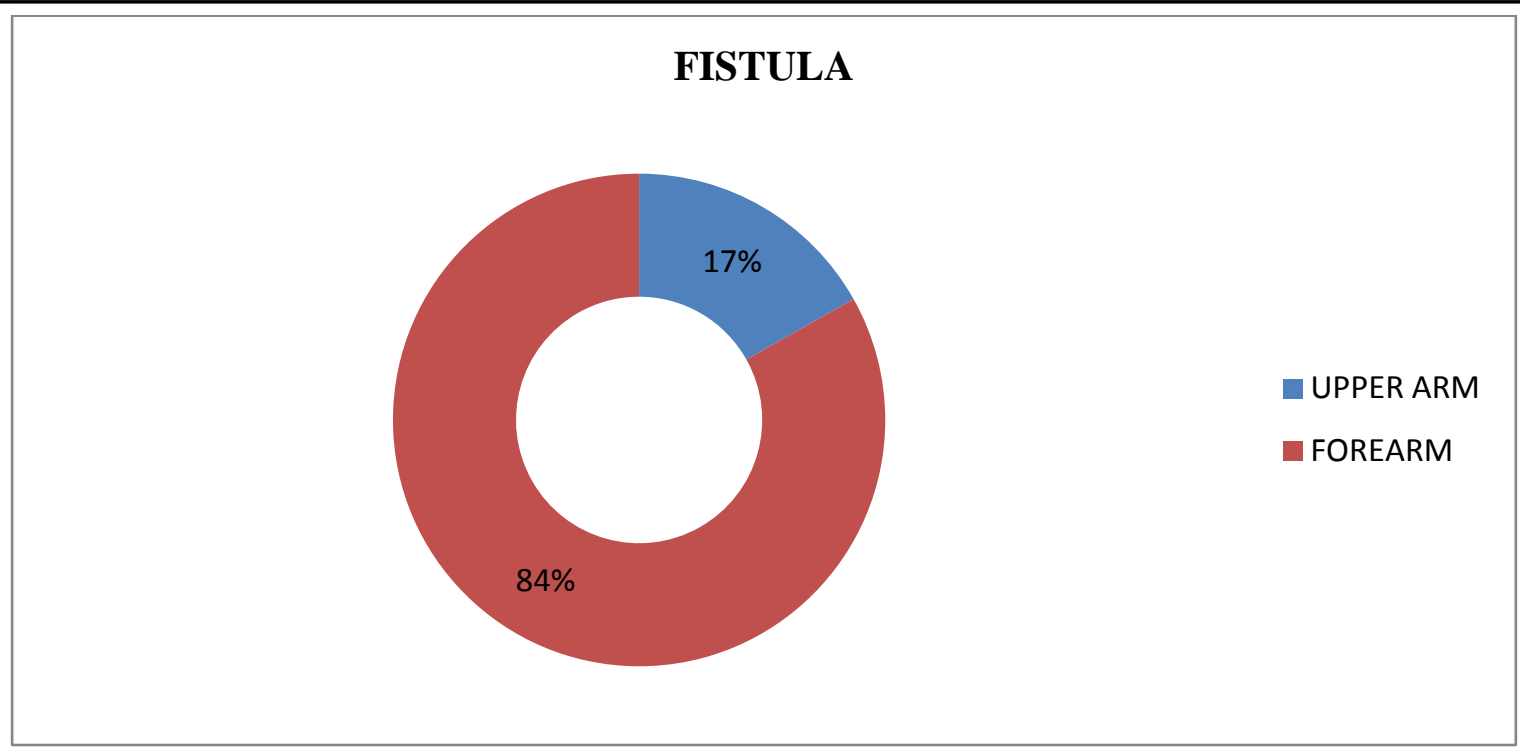

Figure 2-Majority of the Fistulas Created Are in the Forearm.

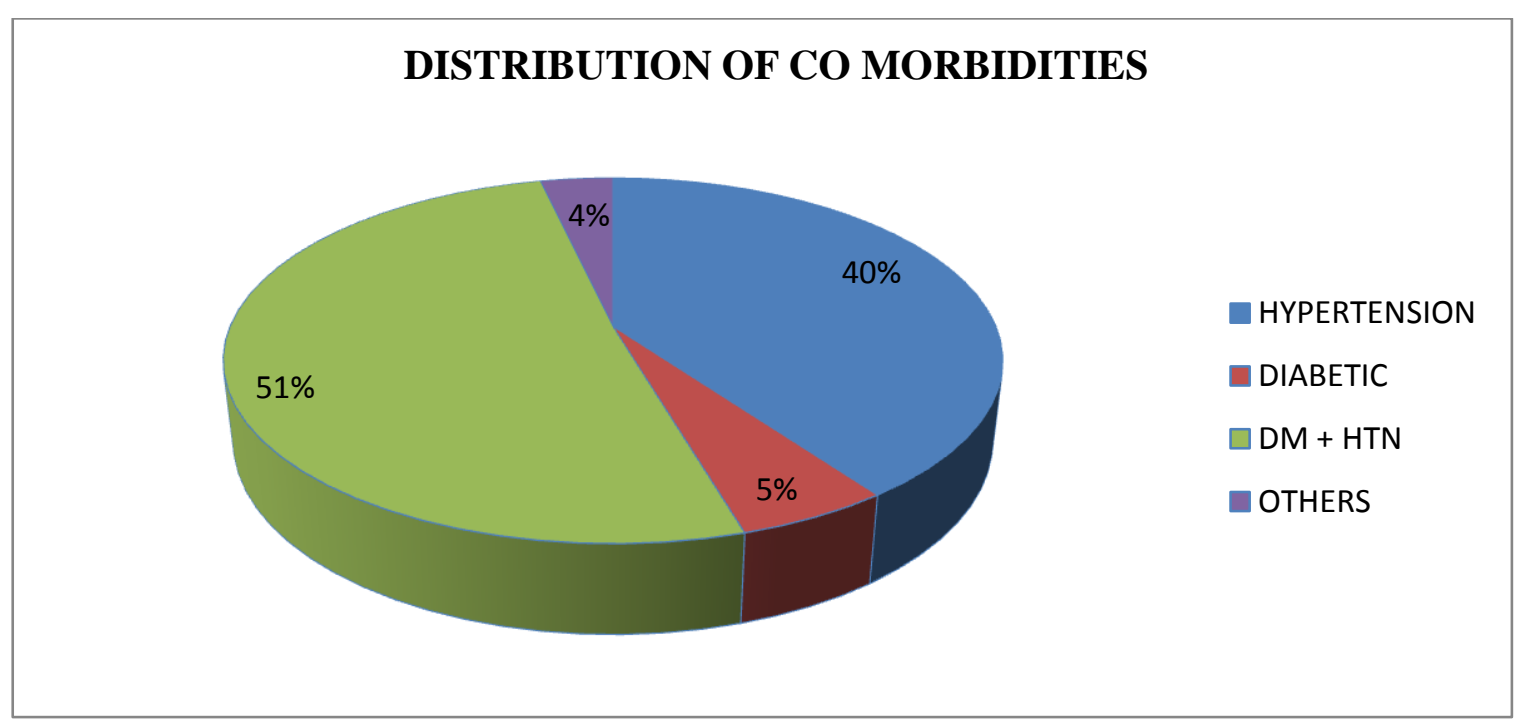

Figure 3- Distribution of Co Morbidities

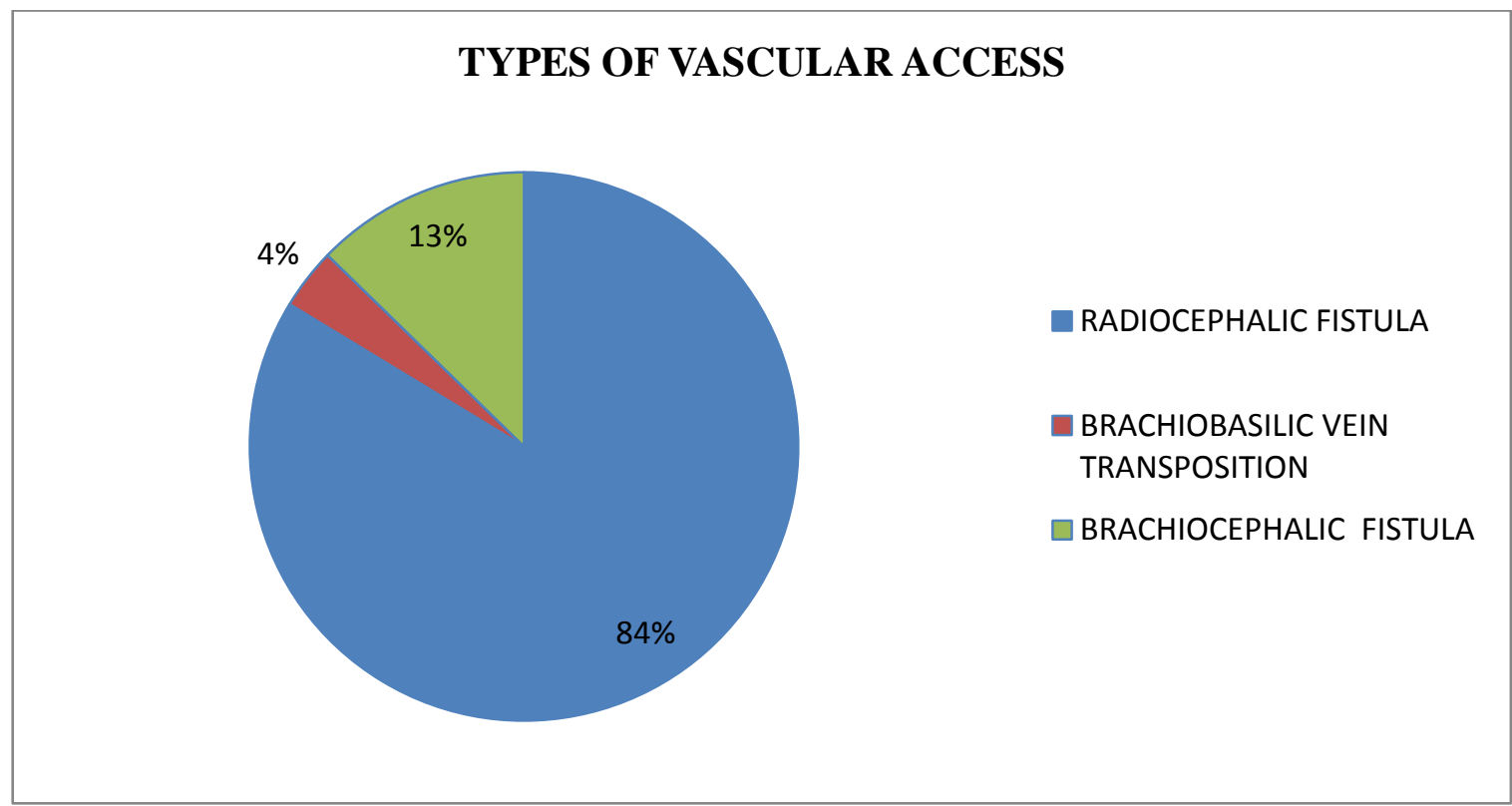

Figure 4- Types Of Vascular Access 


\section{JMSCR Vol||04||Issue||11||Page 13644-13651||November}

Table 1-Calculation of Mean,S tandard Deviation And 95\% CI

\begin{tabular}{|l|c|c|c|c|}
\hline Sl no. & Parameter & Mean & $\begin{array}{c}\text { Standard } \\
\text { deviation }\end{array}$ & $\begin{array}{c}95 \% \text { confidence } \\
\text { interval }\end{array}$ \\
\hline 1 & Age & 51.22 & 12.116 & $47.94-54.49$ \\
\hline 2 & $\begin{array}{c}\text { Vein intima media } \\
\text { thickness }\end{array}$ & 0.28 & 0.04 & $0.19-0.37$ \\
\hline
\end{tabular}

The mean, standard deviation and 95\% confidence interval was calculated for age \& vein intima-media thickness. The mean age of the patient in the study is $(51.2+/-12.1)$ with a standard deviation of (12.1) and 95\% confidence interval of (47.94-54.49). The mean vein intima-media thickmess is $(0.28 \mathrm{~mm})$ with a standard deviation of (0.04) and $95 \%$ confideence interval of (0.19-0.37). The confidence interval achieved assumes significance as all the values are placed on same side of zero.

Table 2-Comparison of Intima Media Thickness and Access Blood Flow Volume

\begin{tabular}{|c|c|c|c|c|c|c|c|c|}
\hline \multirow[t]{3}{*}{ Sl. No } & \multirow{3}{*}{$\begin{array}{l}\text { Access blood } \\
\text { flow volume }\end{array}$} & \multicolumn{4}{|c|}{ Intima-media thickness } & \multirow{3}{*}{$\begin{array}{c}\text { Total } \& \\
\%\end{array}$} & \multirow{3}{*}{$\begin{array}{c}\text { Chi square } \\
\text { value, degree } \\
\text { of freedom }\end{array}$} & \multirow[t]{3}{*}{$\mathrm{p}$ value } \\
\hline & & \multicolumn{2}{|c|}{ Matured } & \multicolumn{2}{|c|}{ Not matured } & & & \\
\hline & & $\mathrm{N}$ & $\%$ & $\mathrm{~N}$ & $\%$ & & & \\
\hline 1 & Matured & 46 & 100 & 0 & 0 & $46(83.6)$ & 55,1 & 0.001 \\
\hline 2 & Not matured & 0 & 0 & 9 & 100 & $9(16.4)$ & & \\
\hline \multicolumn{2}{|c|}{ Total \& \% } & 46 & 83.6 & 9 & 16.4 & $55(100)$ & & \\
\hline
\end{tabular}

The number of matured and immatured cases are same on intima-media thickness and access blood volume criteria. The $\mathrm{p}$ value achieved is significant (0.001)

Table 3-Comparison of Intima-Media Thickness and Vein Diameter

\begin{tabular}{|c|c|c|c|c|c|c|c|c|}
\hline \multirow[t]{3}{*}{ Sl. No } & \multirow{3}{*}{$\begin{array}{c}\text { Vein } \\
\text { diameter }\end{array}$} & \multicolumn{4}{|c|}{ Intima-media thickness } & \multirow{3}{*}{$\begin{array}{c}\text { Total \& } \\
\%\end{array}$} & \multirow{3}{*}{$\begin{array}{c}\text { Chi square } \\
\text { value, degree } \\
\text { of freedom }\end{array}$} & \multirow[t]{3}{*}{$\mathrm{p}$ value } \\
\hline & & \multicolumn{2}{|c|}{ Matured } & \multicolumn{2}{|c|}{ Not matured } & & & \\
\hline & & $\mathrm{N}$ & $\%$ & $\mathrm{~N}$ & $\%$ & & & \\
\hline 1 & Matured & 46 & 100 & 6 & 66.7 & $52(94.5)$ & $16.2,1$ & 0.001 \\
\hline 2 & Not matured & 0 & 0 & 3 & 33.3 & $3(5.5)$ & & \\
\hline \multicolumn{2}{|c|}{ Total \& \% } & 46 & 83.6 & 9 & 16.4 & $55(100)$ & & \\
\hline
\end{tabular}

All the 46 cases are matured by both intima-media were not matured by both intima-media thickness thickness and vein diameter, while of the 9 immatured cases, 6 were matured by vein and vein diameter. The $\mathrm{p}$ value achieved is diameter but not by intima-media thickness and 3 significant (0.001)

Table 4-Comparison of Intima-Media Thickness Criteria and Access Flow Volume

\begin{tabular}{|c|c|c|c|c|c|c|c|}
\hline \multirow[t]{3}{*}{ Sl. no } & \multirow{3}{*}{$\begin{array}{l}\text { Intima media } \\
\text { thickness criteria }\end{array}$} & \multicolumn{4}{|c|}{ Access blood flow volume } & \multirow{3}{*}{$\begin{array}{l}\text { Chi square } \\
\text { value, degree } \\
\text { of freedom }\end{array}$} & \multirow[t]{3}{*}{$\mathrm{p}$ value } \\
\hline & & \multicolumn{2}{|c|}{ Matured } & \multicolumn{2}{|c|}{ Not matured } & & \\
\hline & & $\mathrm{N}$ & $\%$ & $\mathrm{~N}$ & $\%$ & & \\
\hline 1 & $</=0.20 \mathrm{~mm}$ & 0 & 0 & 4 & 100 & \multirow[t]{4}{*}{55,2} & \multirow[t]{4}{*}{0.001} \\
\hline 2 & $0.21-0.25 \mathrm{~mm}$ & 0 & 0 & 5 & 100 & & \\
\hline 3 & $>/=0.26 \mathrm{~mm}$ & 46 & 100 & 0 & 0 & & \\
\hline & Total & 46 & 83.6 & 9 & 16.4 & & \\
\hline
\end{tabular}

The intima media thickness were categorized into three subdivisions based on their maturation status. Of 55 cases, 4 cases were showing IMT of $</=0.20 \mathrm{~mm}$ and are not matured by access blood flow volume. 5 cases were showing IMT of 0.21-
$0.25 \mathrm{~mm}$ and are not matured by access blood flow volume. All cases above IMT of $>/=0.26 \mathrm{~mm}$ were matured by access blood flow volume too. The $\mathrm{p}$ value achieved is significant $(0.001)$ 


\section{JMSCR Vol||04||Issue||11||Page 13644-13651||November}

Table 5-Comparison of Intima-Media Thickness Criteria and Vein Diameter

\begin{tabular}{|c|c|c|c|c|c|c|c|}
\hline \multirow[t]{3}{*}{ S1. no } & \multirow{3}{*}{$\begin{array}{l}\text { Intima media } \\
\text { thickness }\end{array}$} & \multicolumn{4}{|c|}{ Vein diameter } & \multirow{3}{*}{$\begin{array}{c}\text { Chi square } \\
\text { value, degree } \\
\text { of freedom }\end{array}$} & \multirow[t]{3}{*}{$\mathrm{p}$ value } \\
\hline & & \multicolumn{2}{|c|}{ Matured } & \multicolumn{2}{|c|}{ Not matured } & & \\
\hline & & $\mathrm{N}$ & $\%$ & $\mathrm{~N}$ & $\%$ & & \\
\hline 1 & $</=0.20 \mathrm{~mm}$ & 0 & 0 & 3 & 100 & \multirow[t]{4}{*}{$40.4,2$} & \multirow[t]{4}{*}{0.001} \\
\hline 2 & $0.21-0.25 \mathrm{~mm}$ & 6 & 100 & 0 & 0 & & \\
\hline 3 & $>/=0.26 \mathrm{~mm}$ & 46 & 100 & 0 & 0 & & \\
\hline & Total & 52 & 94.5 & 3 & 5.5 & & \\
\hline
\end{tabular}

The intima-media thickness were categorized into three subdivisions based on their maturation status. Of 55 cases, 3 cases were showing IMT of $</=0.20 \mathrm{~mm}$ and are not matured by vein diameter. 6 cases were showing IMT of $0.21-0.25 \mathrm{~mm}$ and are found matured by vein diameter. and intimamedia thickness. All cases above IMT of $>/=0.26 \mathrm{~mm}$ were matured by vein diameter too. The $\mathrm{p}$ value achieved is significant $(0.001)$

Table 6-Calculation Of Odd's Ratio With Risk Factors

\begin{tabular}{|c|c|c|c|c|c|}
\hline Sl no. & Risk factors & Category & Odds ratio & $95 \% \mathrm{CI}$ & $\mathrm{p}$ value \\
\hline \multirow[t]{3}{*}{1} & \multirow[t]{3}{*}{ Age } & $20-45$ & 1 & & 0.310 \\
\hline & & $46-55$ & 0.87 & $0.180-4.176$ & 0.85 \\
\hline & & $\geq 56$ & 2.36 & $0.558-10.017$ & 0.28 \\
\hline \multirow[t]{2}{*}{2} & \multirow[t]{2}{*}{ Gender } & Male & 1 & & \\
\hline & & Female & 1.118 & $0.255-4.8$ & 0.8 \\
\hline \multirow[t]{2}{*}{3} & \multirow[t]{2}{*}{ Hypertension } & Yes & 1.714 & $0.17-16.6$ & 0.64 \\
\hline & & No & 1 & & 0.21 \\
\hline \multirow[t]{2}{*}{4} & \multirow[t]{2}{*}{ Diabetes mellitus } & Yes & 1.42 & $0.43-4.7$ & 0.55 \\
\hline & & No & 1 & & 0.02 \\
\hline \multirow[t]{3}{*}{5} & \multirow{3}{*}{$\begin{array}{l}\text { Number of co- } \\
\text { morbidities }\end{array}$} & One & 1 & & 0.03 \\
\hline & & Two & 1.25 & $0.35-4.3$ & 0.72 \\
\hline & & Three & 4.8 & & 1 \\
\hline \multirow[t]{3}{*}{6} & \multirow[t]{3}{*}{ Type of fistula } & Brachiobasilic & & & 0.99 \\
\hline & & Brachio cephalic & 3.77 & $0.73-19.3$ & 0.11 \\
\hline & & Radio cephalic & 1 & & 0.002 \\
\hline
\end{tabular}

AGE-Odd's ratio for patients aged more than 55 years (2.36) have relative increased risk for delaying the maturity of fistula which is associated high confidence interval. This could probably be related to the age related changes in the vasculature and associated comorbidities with increased age.(TABLE 6)

GENDER- Females are associated with a high Odd's ratio of more than 1 indicating higher chance of altering the maturity of AV fistula and with high confidence interval it increases precision of obtained Odd's ratio.

HYPERTENSION- Patients with hypertension are having a Odd's ratio of 1.7 suggesting exposure is associated with higher chance of causing immaturity of AV fistula. There is associated high confidence interval.
DIABETES MELLITUS- Patients with diabetes mellitus are having a Odd's ratio of 1.4 suggesting exposure is associated with higher chance of causing immaturity of $\mathrm{AV}$ fistula. There is associated high confidence interval.

NUMBER OF CO-MORBIDITIES- With increase in the number of co-morbidities there is an increase in Odd's ratio. Patients associated with three co-morbidities have a high Odd's ratio(4.8).

TYPE OF FISTULA- Patients with brachiocephalic fistula (3.7) have high Odd's ratio as compared to radiocephalic fistula(1) suggesting exposure is prone for causing higher chance of immaturity of AV fistula. 


\section{JMSCR Vol||04||Issue||11||Page 13644-13651||November}

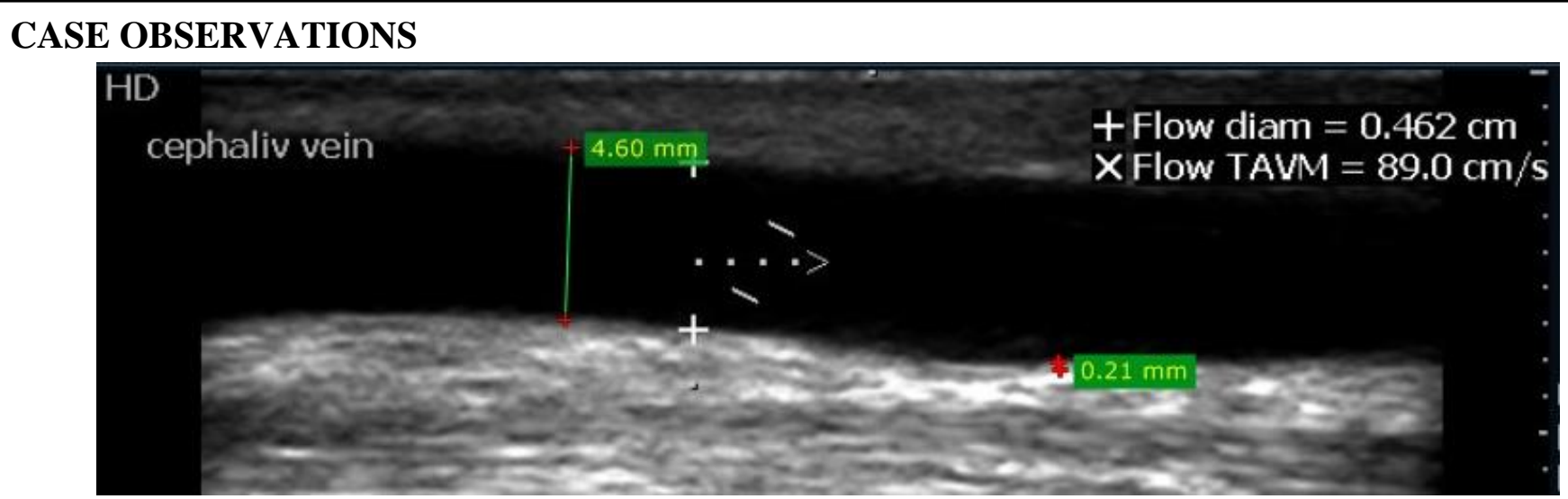

Figure 5-US grayscale image in longitudinal plane demonstrating the intima-media thickness as $0.21 \mathrm{~mm}$

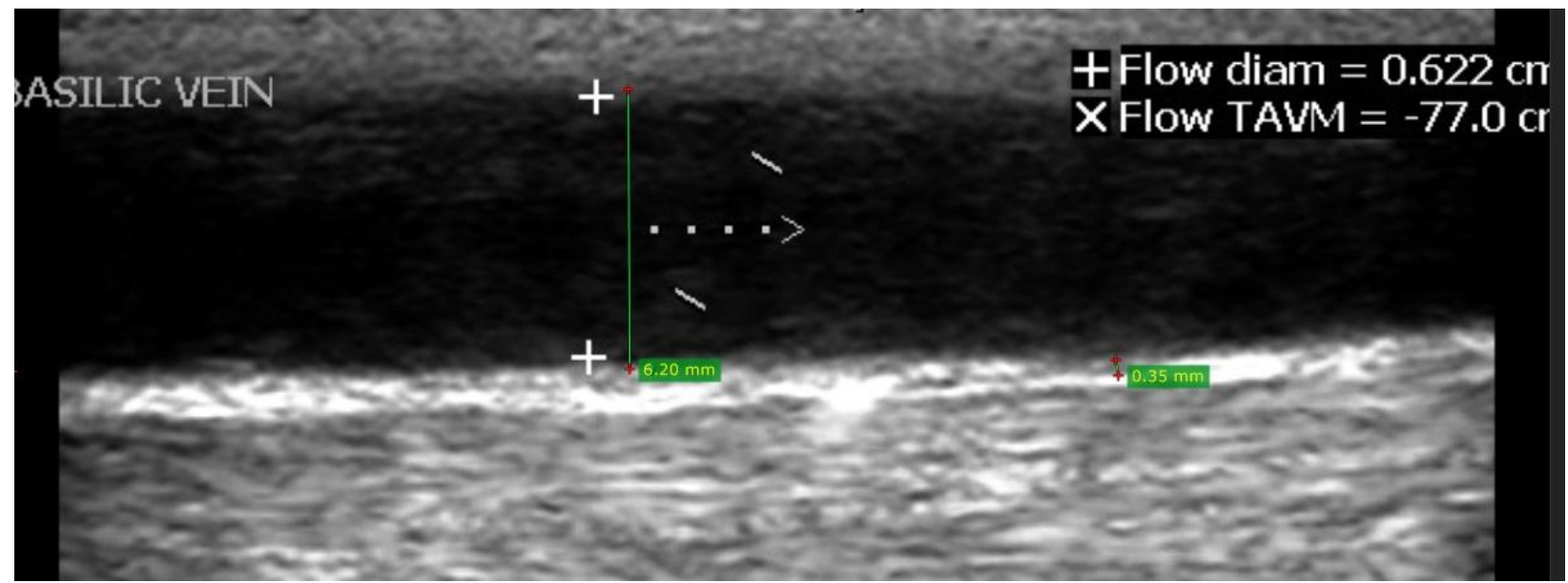

Figure 6-US grayscale image in longitudinal plane demonstrating intima-media thickness as $0.35 \mathrm{~mm}$.

\section{DISCUSSION}

In our study, 52 cases( $94.6 \%)$ were matured and 3 cases $(5.4 \%)$ were not matured. All the immatured cases, developed post procedural complications in the form of thrombosis at the anastomotic site or in the cephalic vein.

Anatomic variation in the form of high origin of radial artery was noted in one case. Few cases showed the bulk of the fistulous flow being drained into basilic vein through the median cubital vein from the cephalic vein and few cases showed communication between superficial veins and the venae comitantes of the deep arteries through which the fistulous flow goes at the level of the elbow.

Venous intima media thickness can be used to assess maturity of AV fistula along with vein diameter and access blood flow volume. Increase in intima-media thickness can increase the probability of maturity of AV fistula. Venous intima-media thickness can be also correlated with the histological examination. The increase in venous intima-media thickness is due to smooth muscle cell proliferation and neointimal hyperplasia.

Compared to the study done by Arash jaberi et al, we did not use very high frequency probes and hoop stress to assess maturity. The minimum intima-media thickness obtained to characterize a fistula as matured is $>/=0.21 \mathrm{~mm}$ in comparison to $0.16 \mathrm{~mm}$ obtained by Arashjaberi et al (12). The probable reason could relate to the high frequency probes that were employed.

\section{CONCLUSION}

Our findings indicate that venous wall intimamedia thickness using US can be used to predict cannulation readiness to maximize successful cannulation and avert AVF damage by premature cannulation. These findings require further study and validation in multicenter prospective studies. Vein intima-media thickness can be used to assess 
maturity and to know the temporal changes in vein since the creation of fistula and can be complementary to other US maturation criteria (vein diameter \& access blood flow volume).

\section{REFERENCES}

1. Vascular Access for Hemo-dialysis. [online]. 2014 [cited 2014 Jul 23]; Available from: URL:http://kidney.niddk.nih.gov/kudiseases/pubs/vascularaccess

2. Umesh Khanna. The economics of dialysis in India. Indian J nephrol2009 Jan;19(1):14.

3. Patrick W, Barbara ND. Colour Doppler ultrasound in dialysis access. Nephrol Dial Transplant 2004;19(8):1956-1963.

4. Teodorsu V, Gustavson S, Schanzer H. Duplex ultrasound evaluation of hemodialysis access: A detailed protocol. International Journal of Nephrology [serial online] 2012 [cited 2012 Jun 19]; 2012[7 screens]. Available from: URL:http://dx.doi.org/10.1155/2012/508956

5. Robbin ML, Chamberlain NE, Lockhart ME, Gallichio MH, Young CJ, Deierhoi $\mathrm{MH}$ et al. Hemodialysis arteriovenous fistula maturity: US evaluation. Radiology 2002 Oct;225(1):59-64.

6. CemY, SunaO, YaseminE, AykutB, HakanO. B- flow sonographic evaluation of hemodialysis fistulas. J Ultrasound Med 2005;24:1503-1508.

7. Couto TMO, Matos H, Moreira A, Estevao A.Ultrasound and the dialysis patient. European Congress of Radiology.2011 Mar; Wein.

8. Paul LA, Paul AD, Myron AP, Norman W. Clinical Doppler ultrasound. China:Elsevier; 2006. 79-80.

9. Paul LA, Paul AD, Myron AP, Norman W. Clinical Doppler ultrasound. China: Elsevier; 2006. 109-111.

10. Singh P, Robbin ML, Lockhart ME, Allon M. Clinically Immature Arteriovenous hemodialysis fistulas: Effect of US on salvage. Radiology 2008 Jan;246(1):299305.

11. Kaushal L, Patil A, Verma VK, Ahirwar $\mathrm{CP}$, Shamim. Vascular mapping before hemodialysis Access in CRF patients and Evaluation of AVF maturation by Doppler Ultrasound. Sch J App Med Sci 2014;2(3A):949-955.

12. Arash J, Derek M, Rosa MM, Niki D, Adrien B. Arteriovenous Fistulas for Hemodialysis: Application of High Frequency US to Assess Vein Wall Morphology for Cannulation Readiness. Radiology 2011 Nov;261(2):616-624.

13. David EF, Deborah GL, Mary CF, Janis GL.Duplex and ColorDoppler Sonography of HemodialysisArteriovenous Fistulas and Grafts. Radiographics 1993; 13:983999.

14. RobbinML.,GreeneT,Cheung AK, Allon M, Berceli SA et al. Arteriovenous Fistula Development in the First 6 Weeks after Creation.Radiology 2016 May; 279:620629. 